\title{
Sweet Treats Sweet: A Review of Antidiabetic Properties of Honey
}

\author{
Mohammed Taha Al-Hariri ${ }^{1}$ \\ ${ }^{1}$ Department of Physioloy, College of Medicine, Imam Abdulrahman Bin Faisal University, Dammam, Saudi \\ Arabia \\ Correspondence: Mohammed Taha Al-Hariri, Department of Physiology, College of Medicine, Imam \\ Abdulrahman Bin Faisal University, P O Box 2114-31451, Dammam, Saudi Arabia. E-mail: \\ mtalhariri@iau.edu.sa
}

\author{
Received: March 25, 2018 Accepted: April 26, 2018 Online Published: April 28, 2018 \\ doi:10.5539/gjhs.v10n6p94 URL: https://doi.org/10.5539/gjhs.v10n6p94
}

\begin{abstract}
Diabetes mellitus is a chronic progressive disease that cannot be effectively controlled with single therapy and diabetic patients struggle to maintain the recommended blood glucose control. This increases the risk for many complications such as macro and micro vascular diseases, neuropathy

Retinopathy, and diabetic foot. Honey has been used to prevent and treat many diseases. The mechanisms behind its biological and pharmacological role are still not clearly understood, however, some studies reported that Honey has antimicrobial, antioxidant, and immune stimulation actions. The aim of this article was to review the published articles about the antidiabetic properties of honey with their mechanisms. The findings showed that low glyceamic index honey can act as hypoglyceamic agent and delay or prevents the progression of the diabetic outcomes. However further studies to standardize the use of honey among patients with Diabetes mellitus are need.
\end{abstract}

Keywords: honey, diabetes, antioxidant and hypolipidemic.

\section{Introduction}

Diabetes mellitus (DM) is one of the most common endocrine disorder that manifested by abnormal metabolism of glucose and lipids as a result of direct or indirect insulin action and/or secretion. (Pontiroli, 2004) DM is characterized by pancreatic morphological defect associated with high blood glucose, lipid and many other organs defect due to progressive metabolic derangement (Soret et al., 1974; Lencioni et al., 2008).

Intensive hyperglyceamia therapies are highly needed to control the glyceamic and lipidemic changes and to delay or prevent the Diabetic complications such as stroke, diabetic foot, retinopathy nephropathy and neuropathy (Folli et al., 2011).

Unfortunately, DM is a chronic progressive disorder which cannot be efficiently controlled with single therapy (Group 1995b; Yale et al., 2001). Diabetic patients have difficulty in maintaining and/or achieving the recommended blood glucose control. This increases the risks for many complications (Group 1995a; Group 2012). Furthermore, oxidative stress is contributed significantly in the pathophysiological mechanisms of diabetes. Depleted levels of antioxidant enzymes with excessive production of reactive oxygen species and high levels of oxidative stress have been demonstrated in many Diabetic clinical and experimental studies (Turk et al., 2002; Al-Hariri et al., 2011).

There is an increasing advocacy of natural products in the treatment of DM and its complications, as the use of chemical drugs are not curative and costly (Al-Hariri, 2011).

The promising findings of honey in many clinical and experimental trials have attracted scientist attention as an alternative medicine for DM and it has been reevaluated in a more scientific settings (Abdulrhman et al., 2013; Erejuwa et al., 2016).

Honey produced from the plant's exudation and nectar by the bees (Alvarez-Suarez et al., 2010).

These days, honey believed to be medicine and nutrition. In the modern medicine this message, has been considered as conventional pharmaceutical approaches by the general public. Accordingly, a new branch of alternative medicine has been developed called Apitherapy that uses honey bee products including honey, propolis, bee bread, bee venom, royal jelly and pollen in the treatment and prevention of diseases (Ghosh \& Playford, 2003). Scientific finding indicated that honey has been used for the treatment of many diseases such as urinary, 
respiratory and gastrointestinal (Zaghloul et al., 2001) and in local diseases such wounds (Al-Hariri, 2013), psoriasis (Al-Waili, 2003), radiation mucositis(Moolenaar et al., 2006), eczema, dermatitis and diaper (Al-Waili 2003, 2005). Summarizing of biological and functional properties of honey shown in Table 1.

Table 1. Biological and functional Properties of Honey

\begin{tabular}{l}
\hline Biological Properties of Honey \\
\hline Hypolipidemic \\
Cardiocascular disaeses \\
Antioxidant \\
Antiinflammatory \\
Wound care \\
Antitumor \\
Gastrointestinal diseases \\
Antimicrobial \\
Oral Health \\
Athletic performance
\end{tabular}

This is a review of scientific studies that highlight the antidiabetic properties of using honey in DM.

\section{Materials and Methods}

A systematic approach was taken to identify scientific articles that studied the antidiabetic properties of honey in diabetes mellitus. I searched CAM-PubMed, MEDLINE, Cochrane Library Database, google scholar and OLDMEDLINE published in the English language between 1970 to 2017 using the MeSH terms honey, alternative therapies, hypoglyceamic, antioxidant, hypolipidemic and Apitherapy each crossed with the term diabetes mellitus including clinical and experimental studies.

\section{Results and Discussion}

\subsection{Composition of Honey}

Honey is very rich natural compound produced by bees from nectar "sugar rich liquid produced by flowers and plants" after modifying, adding and storing in the honeycombs (Manyi-Loh et al., 2011). Previous published studies have identified 200 compounds of honey including vitamins, minerals complex, mixture of saccharides, enzymes, proteins, amino acid, peptides, polyphenols, organic acids and carotenoid (Gheldof et al., 2002; Sato \& Miyata, 2000).

There are different types of honey available based on the flower from which bees gather the nectar (Bogdanov, 2009).

The carbohydrates are the main ingredient of honey (95\%). The main sugar is monosaccharaides (glucose or/and fructose). Moreover, honey contains many other compounds such as vitamins, proteins, amino acids and organic acids (Bogdanov et al., 2008). The second important component of honey is water. Its concentration depends mainly on treatment of honey during extraction and storage, nectar conditions, humidity inside the hive and weather (Molan 2001). Honey also contains minerals (sodium potassium and calcium) and trace minerals (manganese, zinc, copper and iron) that are essential for many physiological mechanisms and catalysts various metabolic reactions, which indicate that honey contributes significantly on nutritional value and prevention or healing of illness(McKee, 2003). Choline is other vital compound of honey which showed many important biological properties essential for the brain function and other system such as cardiovascular as well as for cellular membrane repair and composition (Bogdanov et al., 2008). Honey has very strong antioxidant compound known as Aroma. This compound differs with geographical and botanical origin. It has been reported that Aroma contains 500 volatile compounds were found in different types of honey (Bogdanov et al., 2004).

Phytochemicals compounds of honey such as flavonoids, phlobtannins, terpenoids, alkaloids, phenols, saponins, tannins and glycosides, are now recognized to have a positive health effects (Liu, 2004). Bees that fed on valuable herbals extracts has shown many beneficial medicinal activities than normal honey (Rosenblat et al., 1997). 
Polyphenols are the largest phytochemical antioxidant compounds (Tomás-Barberán et al., 2001), but when honey stored for log time or treated with mild heat, a compositional change can occur due to decomposition of fructose and caramelization of the carbohydrates contents of honey (Villamiel et al., 2001).

\subsection{Antidiabetic Properties}

There are different proposed mechanisms summarized the antidiabetic properties of honey showed in Figure 1.

The impact of sweets on health is assessed by the calculation of how the sweets containing foods affect the level of blood sugar. Today, the sweets containing foods are often rated in terms of the glyceamic index.

Sweet containing food with a low glyceamic index induces a little change in blood glucose, while that with a high glyceamic index cause blood glucose to swings (Brand-Miller et al., 2003). According to the international table of glyceamic index "diets with glyceamic index of 0.55 or less are considered low glyceamic index diets and the glyceamic index of eleven types of honey was 0.55 ( \pm 0.05$)$ "(Foster-Powell et al., 2002). Many studies, reported that, consumption of high glyceamic index food is a significant risk factor for diabetic patient (Liu et al., 2001). Fortunately, it was found that some types of honey (such as yellow box and acacia) with relatively high concentration of monosaccharide (fructose) have a lower glyceamic index (Ischayek \& Kern, 2006), that might be make low glyceamic index honey a very useful alternative sweeteners (Ludwig, 2000), plus it's benefits with respect to diabetes and/or its complications (Jenkins et al., 2002).

Because of its nutritional values, consumption of low glyceamic index honey might have many pharmacological and biological properties and could be consumed by patients with diabetes mellitus. It has been reported significant reduction plasma glucose level induced by honey (Al-Waili, 2003, 2004) with significant increase in insulin secretion (Al-Waili, 2004). An experimental study in normal rats, showed significant reduction in glycated hemoglobin with honey supplementation (Chepulis \& Starkey, 2008).

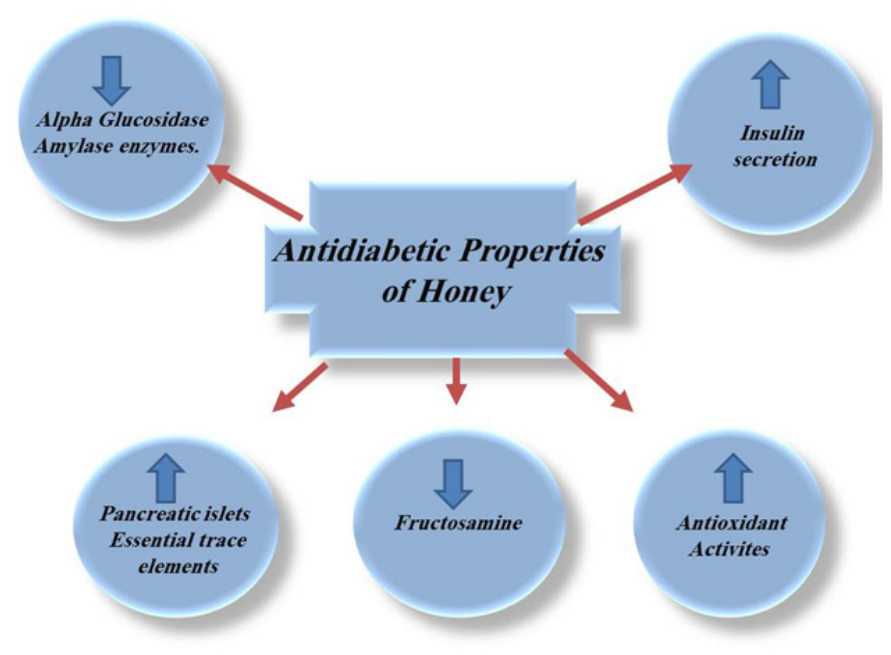

Figure 1. Antidiabetic Properties of Honey

Honey was efficacious and well tolerated by diabetic patients (Katsilambros et al., 1988; Samanta et al., 1985). Overall, consumption of $50 \mathrm{~g}$ honey of unspecified type by patients with diabetes resulted in minimal increases of blood glucose and insulin compared with the intake of the same amounts of sweets mixture resembling to honey (Al-Khalidi et al., 1980).

Chronic hyperglyceamia in diabetes, seen in experimental animal and human studies induces free radicals generation and oxidative stress, which deplete the activity of free radical scavenging enzymes (Tomás - Barberán et al., 2001; Telci et al., 2000). The pancreatic b-cells are highly susceptible to oxidative stress and damage because they have low activity of scavenging enzymes, which are the first line of defense against the toxicity of oxidative insult (Lenzen 2008). It is well known that glucose toxicity induces oxidative stress which is involved in b-cell dysfunction. Thus, antidiabetic properties of honey can protect against oxidative stress (Erejuwa et al., 2010b). Erejuwa and his colleagues in 2010 recommended that good management of diabetes mellitus can be achieved by combing honey as antioxidant agent with antidiabetic drugs in the (Erejuwa et al., 2010b).

Some authors attributed the antidiabetic effect of honey to the potential role of fructose (Deibert et al., 2010). 
Honey significantly decreased fructosamine levels providing additional metabolic benefits in diabetes mellitus not achieved with other hypoglyceamic agent (Erejuwa et al., 2011a). Fructosamine is a modified protein by glucose. It can undergo oxidative cleavages result in generation of reactive oxygen species. Fructosamine was significantly elevated in diabetic rats and strongly associated with diabetes mellitus and/or its complications (Kennedy and Baynes 1984). All these findings have been confirmed histologically, significant improvement in pancreatic islets with enhanced insulin secretion were observed diabetic rats treated with sweets (honey) (Erejuwa et al., 2010b).

Studies have also shown that honey can helps in controlling some risk factors. It significantly controlled energy /food intake and body weight in rats (Chepulis, 2007). Study has shown that leptin level in rats treated with honey was lower than in those given sucrose (Nemoseck et al., 2011).

In addition to constituents, honey contains fructooligosaccharides which have prebiotic benefits (Chow, 2002; Sanz et al., 2005). Different studies in obese subjects have been reviewed by Everad and Cani (2013) reported many physiological effects of prebiotic treatment on lipids, inflammatory markers and glucose level. Evidence suggests reduction in appetite, gut metabolic endotoxin producing bacteria, gut barrier dysfunction and low-grade inflammatory markers following prebiotic therapy in obese and Diabetic person (Everard \& Cani, 2013).

Numerous studies found that, deficiencies of trace-elements are frequently associated to problems with its absorption or chronic diseases. Significant alterations have found in the status of some micronutrients in diabetic patients and on the other hand, deficiency of some of these nutrients has been correlated with Diabetes mellitus and/or its outcomes (Bhanot et al., 1994; Zargar et al., 1998).

Honey may mediate antidiabetic control and insulin secretion through its minerals constituents "such as Zinc, Manganese Copper, Selenium, Chromium, Calcium, Potassium, etc.” (Bogdanov et al., 2008). Clinical research reported that, early alterations of specific trace-elements may contribute to impaired insulin and glucose metabolism. Vice versa, diabetes mellitus is associated with disturbance of some trace elements (Zargar et al., 2002).

Deficiencies of some trace-elements "Zinc, Chromium and Manganese" increase a person's risk for developing glucose intolerance and diabetic complications (Chen et al., 1995). Zinc is directly involved in the synthesis, storage, secretion, as well as conformational integrity of insulin and that $\mathrm{Zn}$ assembles to a dimeric form for storage and secretion as crystalline insulin (Chausmer, 1998). Lower level of Zinc may affect the pancreatic cells ability for the synthesis and secretion of insulin in patient with type-2 diabetes mellitus (DiSilvestro, 2000).

Ingestion of low glyceamic index multifloral honey has given rise to a significant decrease in blood glucose (Soylu et al., 2016), which makes consumption of honey suitable for diabetic patients, not only as nature's sweetener, but for its pharmacological properties too. However, since the chemical constituents in honey vary depending upon the botanical and geographical origins, cautious consumption by diabetic patients is recommended, especially when the glyceamic index of honey is unknown.

More recently, honey was found to have a significant inhibitory effect in vitro medium against alpha glucosidase and amylase enzymes. These enzymes are responsible for converting complex starch molecule in to sugar, a competitive inhibition of glucosidase and amylase enzymes by honey could help diabetic patient in glyceamic control at faster rates (Krishnasree \& Ukkuru, 2017).

\subsection{Antioxidant and Hypolipidemic effects}

Oxidation and hyperlipidemia are a major deteriorative factors in the genesis of diabetes mellitus or/and its complications (Simmons, 2012). Both animal experimental and human studies, diabetes mellitus is associated with significant depleted of free radical scavenging activity and high oxidative stress due to the chronic hyperglyceamia (Turk et al., 2002), which induced activation of many oxidative stress mechanisms play an essential role in the development of impaired insulin secretion and/or resistance as in type 2 and complications of both types of diabetes mellitus (Evans et al., 2003).

Studies reported that, administered of honey alone or with conventional agents have demonstrated a novel antioxidant in the management of chronic diseases (Erejuwa et al., 2012; Erejuwa et al., 2011b).

Erejuwa and his team (2010) attributed the antidiabetic effect of honey to its antioxidant activities on the pancreatic cells against Streptozotocin-induced diabetic oxidative stress (Erejuwa et al., 2010a).

Al-Waili (2004) found that honey can improved lipid profile as well decreased triacylglycerol in patients with hypertriglyceridemia (Al-Waili 2004). The ability of honey to modulate lipid and metabolic profile carries a potential role of using honey to reduce cardiovascular risk factors in diabetes mellitus. Yaghoobi (2008) recommended the consumption of honey to reduce diabetic complications such as cardiovascular, particularly in 
subjects with elevated risk factors. Other favor he found that honey does not increase body weight in overweight or obese subjects (Yaghoobi et al., 2008).

\section{Conclusion}

In conclusion, because of its positive nutritional and physiological effects, honey has remarkable antidiabetic, hypolipidemic and antioxidant properties which might be considered in future therapeutic trials targeting beta cells of pancreas.

\section{Competing Interests Statement}

The author declares that there are no competing or potential conflicts of interest.

\section{References}

Abdulrhman, M., El Hefnawy, M., Ali, R., Hamid, I. A., El-Goud, A. A., and Refai, D. (2013). Effects of honey, sucrose and glucose on blood glucose and C-peptide in patients with type 1 diabetes mellitus. Complement Ther Clin Pract, 19(1), 15-19. https://doi.org/10.1016/j.ctcp.2012.08.002

Al-Hariri, M., Eldin, T. G., Abu-Hozaifa, B., and Elnour, A. (2011). Glycemic control and anti-osteopathic effect of propolis in diabetic rats. Diabetes, Meta Syndr Obes: targets and therapy, 4, 377. https://doi.org/10.2147/DMSO.S24159

Al-Hariri, M. T. (2011). Propolis and its direct and indirect hypoglycemic effect. $J$ Family and Community Med, 18(3), 152. https://doi.org/10.4103/2230-8229.90015

Al-Hariri, M. T. (2013). The Local Effects of Honey on Diabetic Foot Disorder. Pak J Physiol, 9(1).

Al-Khalidi, A., Jawad, F. H., and Tawfiq, N. H. (1980). Effects of bees honey, zahdi date and its syrup on blood glucose and serum insulin of diabetics. Nutrition reports international, 21(5), 631-43.

Al-Waili, N. (2005). Clinical and mycological benefits of topical application of honey, olive oil and beeswax in diaper dermatitis. Clin Microbal Infect, 11(2), 160-63. https://doi.org/10.1111/j.1469-0691.2004.01013.x

Al-Waili, N. S. (2003). Topical application of natural honey, beeswax and olive oil mixture for atopic dermatitis or psoriasis: partially controlled, single-blinded study. Complement Ther Med, 11(4), 226-34.

1-Waili, N. (2004). Natural honey lowers plasma glucose, C-reactive protein, homocysteine, and blood lipids in healthy, diabetic, and hyperlipidemic subjects: comparison with dextrose and sucrose. J Med Food, 7(1). https://doi.org/10.1089/109662004322984789

Ali-Wali, N. (2003). Intrapulmonary administration of natural honey solution, hyperosmolar dextrose or hyposmolar distilled water to normal individuals and to patients with type-2 diabetes mellitus or hypertension: their effects on blood glucose level, plasma insulin and C-peptide, blood pressure and peaked expiratory flow rate. Eur J Med Res, 31, 295-303. https://doi.org/10.1016/S0965-2299(03)00120-1

Alvarez-Suarez, J. M., Tulipani, S., Romandini, S., Bertoli, E., and Battino, M. (2010). Contribution of honey in nutrition and human health: a review. Mediterr $J$ Nutr Metab, 3(1), 15-23. https://doi.org/10.1007/s12349-009-0051-6

Bhanot, S., Thompson, K., and McNeill, J. (1994). Essential trace elements of potential importance in nutritional management of diabetes mellitus. Nutrition Research, 14(4), 593-604. https://doi.org/10.1016/S0271-5317(05)80223-4

Bogdanov, S. (2009). Honey composition. The honey book.

Bogdanov, S., Jurendic, T., Sieber, R., and Gallmann, P. (2008). Honey for nutrition and health: a review. J Am Coll Nutr, 27(6), 677-89. https://doi.org/10.1080/07315724.2008.10719745

Bogdanov, S., Ruoff, K., and Persano Oddo, L. (2004). Physico-chemical methods for the characterisation of unifloral honeys: a review. Apidologie, 35(1), 4-17. https://doi.org/10.1051/apido:2004047

Brand-Miller, J., Hayne, S., Petocz, P., and Colagiuri, S. (2003). Low-Glycemic Index Diets in the Management of Diabetes A meta-analysis of randomized controlled trials. Diabetes care, 26(8), 2261-67. https://doi.org/10.2337/diacare.26.8.2261

Chausmer, A. B. (1998). Zinc, insulin and diabetes. $J$ Am Coll Nutr, 17(2), 109-15. https://doi.org/10.1080/07315724.1998.10718735

Chen, M.-D., Lin, P.-Y., Tsou, C.-T., Wang, J.-J., and Lin, W.-H. (1995). Selected metals status in patients with noninsulin-dependent diabetes mellitus. Biol Trace Elem Res, 50(2), 119-24. 
https://doi.org/10.1007/BF02789414

Chepulis, L. (2007). The Effect of Honey Compared to Sucrose, Mixed Sugars, and a Sugar - Free Diet on Weight Gain in Young Rats. J Food sci, 72(3), S224-S29. https://doi.org/10.1111/j.1750-3841.2007.00286.x

Chepulis, L. and Starkey, N. (2008). The Long - Term Effects of Feeding Honey Compared with Sucrose and a Sugar - Free Diet on Weight Gain, Lipid Profiles, and DEXA Measurements in Rats. J Food sci, 73(1), H1-H7. https://doi.org/10.1111/j.1750-3841.2007.00592.x

Chow, J. (2002). Probiotics and prebiotics: a brief overview. $J$ Ren Nut, 12(2), 76-86. https://doi.org/10.1053/jren.2002.31759

Deibert, P., König, D., Kloock, B., Groenefeld, M., and Berg, A. 2010. Glycaemic and insulinaemic properties of some German honey varieties. Eur J Clin Nutr, 64(7), 762-64. https://doi.org/10.1038/ejen.2009.103

DiSilvestro, R. A. (2000). Zinc in relation to diabetes and oxidative disease. $J$ Nutr, 130(5), 1509S-11S. https://doi.org/10.1093/jn/130.5.1509S

Erejuwa, O., Sulaiman, S., Wahab, M., Sirajudeen, K., Salleh, M. M., \& Gurtu, S. (2010). a. 'Antioxidant protection of Malaysian tualang honey in pancreas of normal and streptozotocin-induced diabetic rats. Ann Endocrinol, 71(4), 291-6. https://doi.org/10.1016/j.ando.2010.03.003

Erejuwa, O. O., Sulaiman, S. A., \& Ab Wahab, M. S. (2012). Honey: a novel antioxidant. Molecules, 17(4), 4400-23. https://doi.org/10.3390/molecules 17044400

Erejuwa, O. O., Sulaiman, S. A., Ab Wahab, M. S., Sirajudeen, K. N. S., Salleh, M. S. M., \& Gurtu, S. (2011a). Glibenclamide or metformin combined with honey improves glycemic control in streptozotocin-induced diabetic rats. Int J Biol Sci, 7(2), 244. https://doi.org/10.7150/ijbs.7.244

Erejuwa, O. O., Sulaiman, S. A., Wahab, M. S. A., Salam, S. K. N., Salleh, M. S. M., \& Gurtu, S. (2011b). Comparison of antioxidant effects of honey, glibenclamide, metformin, and their combinations in the kidneys of streptozotocin-induced diabetic rats. Int J Mol Sci, 12(1), 829-43. https://doi.org/10.3390/ijms12010829

Erejuwa, O. O., Sulaiman, S. A., Wahab, M. S. A., Sirajudeen, K. N. S., Salleh, M. S. M., \& Gurtu, S. (2010b). Antioxidant protective effect of glibenclamide and metformin in combination with honey in pancreas of streptozotocin-induced diabetic rats. Int J Mol Sci, 11(5), 2056-66. https://doi.org/10.3390/ijms11052056

Evans, J. L., Goldfine, I. D., Maddux, B. A., \& Grodsky, G. M. (2003). Are Oxidative Stress- Activated Signaling Pathways Mediators of Insulin Resistance and $\beta$-Cell Dysfunction? Diabetes, 52(1), 1-8. https://doi.org/10.2337/diabetes.52.1.1

Everard, A., \& Cani, P. D. (2013). Diabetes, obesity and gut microbiota. Best Pract Res Clin Gastroenterol, 27(1), 73-83. https://doi.org/10.1016/j.bpg.2013.03.007

Folli, F., Corradi, D., Fanti, P., Davalli, A., Paez, A., Giaccari, A., Perego, C., \& Muscogiuri, G. (2011). The role of oxidative stress in the pathogenesis of type 2 diabetes mellitus micro-and macrovascular complications: avenues for a mechanistic-based therapeutic approach. Cur Diabetes Rev, 7(5), 313-24. https://doi.org/10.2174/157339911797415585

Foster-Powell, K., Holt, S. H., and Brand-Miller, J. C. (2002). International table of glycemic index and glycemic load values: (2002). Am J Clin Nutr, 76(1), 5-56. https://doi.org/10.1093/ajcn/76.1.5

Gheldof, N., Wang, X.-H., and Engeseth, N. J. (2002). Identification and quantification of antioxidant components of honeys from various floral sources. $J$ Agric Food Chem, 50(21), 5870-77. https://doi.org/10.1021/jf0256135

Ghosh, S. and Playford, R. J. (2003). Bioactive natural compounds for the treatment of gastrointestinal disorders. Clin Sci, 104(6), 547-56. https://doi.org/10.1042/CS20030067

Group, T. S. (2012). A clinical trial to maintain glycemic control in youth with type 2 diabetes. $N$ Engl $J$ Med, 366(24), 2247. https://doi.org/10.1056/NEJMoa1109333

Group, U. P. D. S. (1995a). UK Prospective Diabetes Study 16: overview of 6 years' therapy of type II diabetes: a progressive disease. Diabetes, 44(11), 1249-58. https://doi.org/10.2337/diab.44.11.1249

Group, U. S. (1995b). UKPDS 16. Overview of 6 years' therapy of type II diabetes: a progressive disease. UK Prospective Diabetes Study Group. Diabetes, 44, 1249-58.

Ischayek, J. I., \& Kern, M. (2006). US honeys varying in glucose and fructose content elicit similar glycemic 
indexes. J Am Diet Assoc, 106(8), 1260-62. https://doi.org/10.1016/j.jada.2006.05.003

Jenkins, D. J., Kendall, C. W., Augustin, L. S., Franceschi, S., Hamidi, M., Marchie, A., Jenkins, A. L., \& Axelsen, M. (2002). Glycemic index: overview of implications in health and disease. Am J Clin Nutr, 76(1), 266S-73S. https://doi.org/10.1093/ajen/76/1.266S

Katsilambros, N. L., Philippides, P., Touliatou, A., Georgakopoulos, K., Kofotzouli, L., Frangaki, D., ... \& Sfikakis, P. (1988). Metabolic effects of honey (alone or combined with other foods) in type II diabetics. Acta diabetologia latina, 25(3), 197-203. https://doi.org/10.1007/BF02624814

Kennedy, L., \& Baynes, J. (1984). Non-enzymatic glycosylation and the chronic complications of diabetes: An overview. Diabetologia, 26(2), 93-98. https://doi.org/10.1007/BF00281113

Krishnasree, V. and Ukkuru, M. P. (2017). In vitro antidiabetic activity and glycemic index of bee honeys. IJTK, 16(1), 134-140.

Lencioni, C., Lupi, R., \& Del Prato, S. (2008). $\beta$-cell failure in type 2 diabetes mellitus. Cur Diab Rep, 8(3), 179-84. https://doi.org/10.1007/s11892-008-0031-0

Lenzen, S. (2008). Oxidative stress: the vulnerable beta-cell. Biochem Soc Trans, 36(3), 343. https://doi.org/10.1042/BST0360343

Liu, H. (2004). Potential synergy of phytochemicals in cancer prevention: mechanism of action. $J$ Nutr, 134(12), 3479S-85S. https://doi.org/10.1093/jn/134.12.3479S

Liu, S., Manson, J. E., Stampfer, M. J., Holmes, M. D., Hu, F. B., Hankinson, S. E., \& Willett, W. C. (2001). Dietary glycemic load assessed by food-frequency questionnaire in relation to plasma high-density-lipoprotein cholesterol and fasting plasma triacylglycerols in postmenopausal women. $\mathrm{Am} \mathrm{J}$ Clin Nutr, 73(3), 560-66. https://doi.org/10.1093/ajcn/73.3.560

Ludwig, D. S. (2000). Dietary glycemic index and obesity. $J N$, 130(2), 280S-83S. https://doi.org/10.1093/jn/130.2.280S

Manyi-Loh, C. E., Clarke, A. M., \& Ndip, R. N. (2011). An overview of honey: therapeutic properties and contribution in nutrition and human health. Afr J Microbiol Res, 5(8), 844-52.

McKee, B. (2003). Prevention of residues in honey: A future perspective. Apiacta, 38, 173-77.

Molan, P. (2001). Why honey is effective as a medicine: 2. The scientific explanation of its effects. Bee World, 82(1), 22-40. https://doi.org/10.1080/0005772X.2001.11099498

Moolenaar, M., Louwrens Poorter, R., Paulus Gerardus Van Der Toorn, P., Willem Lenderink, A., Poortmans, P., \& Cornelis Gerardus Egberts, A. (2006). The effect of honey compared to conventional treatment on healing of radiotherapy-induced skin toxicity in breast cancer patients. Acta Oncol, 45(5), 623-24. https://doi.org/10.1080/02841860600781799

Nemoseck, T. M., Carmody, E. G., Furchner-Evanson, A., Gleason, M., Li, A., Potter, H., Rezende, L. M., ... Kern, M. (2011). Honey promotes lower weight gain, adiposity, and triglycerides than sucrose in rats. Nutr Res, 31(1), 55-60. https://doi.org/10.1016/j.nutres.2010.11.002

Erejuwa, O., Nwobodo, N. N., Akpan, J. L., Okorie, U. A., Ezeonu, C. T., Ezeokpo, B. C., ... Sulaiman, S. (2016). Nigerian Honey Ameliorates Hyperglycemia and Dyslipidemia in Alloxan-Induced Diabetic Rats. Nutrients, 24(3), 95. https://doi.org/10.3390/nu8030095

Pontiroli, A. (2004). Type 2 diabetes mellitus is becoming the most common type of diabetes in school children. Acta diabetol, 41(3), 85-90. https://doi.org/10.1007/s00592-004-0149-8

Rosenblat, G., Angonnet, S., Goroshit, A., Tabak, M., \& Neeman, I. (1997). 'Antioxidant properties of honey produced by bees fed with medical plant extracts.' in Antioxidant properties of honey produced by bees fed with medical plant extracts, Bee Product, 49-55. https://doi.org/10.1007/978-1-4757-9371-0_5

Samanta, A., Burden, A., \& Jones, A. (1985). Plasma glucose responses to glucose, sucrose, and honey in patients with diabetes mellitus: an analysis of glycaemic and peak incremental indices. Diabet Med, 2(5), 371-73. https://doi.org/10.1111/j.1464-5491.1985.tb00654.x

Sanz, M. L., Polemis, N., Morales, V., Corzo, N., Drakoularakou, A., Gibson, G. R., \& Rastall, R. A. (2005). In vitro investigation into the potential prebiotic activity of honey oligosaccharides. J Agric Food Chem, 53(8), 2914-21. https://doi.org/10.1021/jf0500684 
Sato, T., \& Miyata, G. (2000). The nutraceutical benefit, part III: honey. Nutrition, 16(6), 468-69. https://doi.org/10.1016/S0899-9007(00)00271-9

Simmons, R. A. (2012). Developmental origins of diabetes: the role of oxidative stress. Free Radic Biol Med, 26(5), 701-08. https://doi.org/10.1016/j.freeradbiomed.2005.12.018

Soret, M., Dulin, W., Mathews, J., \& Gerritsen, G. (1974). Morphologic abnormalities observed in retina, pancreas and kidney of diabetic Chinese hamsters. Diabetologia, 10(1). 567-79. https://doi.org/10.1007/BF01221988

Soylu, M., Atayoğlu, T., İnanç, N., \& Silici, S. (2016). Glycemıc index values of multıfloral Turkish honeys and effect of their consumption on glucose metabolism. $J$ Apic Res, 1-8. https://doi.org/10.1080/00218839.2015.1131454

Telci, A., Çakatay, U., Salman, S., Satman, I. L., \& Sivas, A. (2000). Oxidative protein damage in early stage Type 1 diabetic patients. Diabetes Res Clin Pract, 50(3), 213-23. https://doi.org/10.1016/S0168-8227(00)00197-2

Tomás - Barberán, F. A., Martos, I., Ferreres, F., Radovic, B. S., \& Anklam, E. (2010). HPLC flavonoid .profiles as markers for the botanical origin of European unifloral honeys. J Sci Food Agric, 81(5), 485-96. https://doi.org/10.1002/jsfa.836

Turk, H., Sevinc, A., Camci, C., Cigli, A., Buyukberber, S., Savli, H., \& Bayraktar, N. (2002). Plasma lipid peroxidation products and antioxidant enzyme activities in patients with type 2 diabetes mellitus. Acta diabetol, 39(3), 117-22. https://doi.org/10.1007/s005920200029

Villamiel, M., del Castillo, M. D., Corzo, N., \& Olano, A. (2001). Presence of furosine in honeys. J Sci Food Agric, 81(8), 790-93. https://doi.org/10.1002/jsfa.874

Yaghoobi, N., Al-Waili, N., Ghayour-Mobarhan, M., Parizadeh, S., Abasalti, Z., Yaghoobi, Z., Y... Aghasizadeh, R. (2008). Natural honey and cardiovascular risk factors; effects on blood glucose, cholesterol, triacylglycerole, CRP, and body weight compared with sucrose. TheScientificWorldJournal, 8, 463-69. https://doi.org/10.1100/tsw.2008.64

Yale, J.-F. o., Valiquett, T. R., Ghazzi, M. N., Owens-Grillo, J. K., Whitcomb, R. W., \& Foyt, H. L. (2001). The effect of a thiazolidinedione drug, troglitazone, on glycemia in patients with type 2 diabetes mellitus poorly controlled with sulfonylurea and metformin: A multicenter, randomized, double-blind, placebo-controlled trial. Inn Ann $\quad$ Med, 34 349_Part_1), https://doi.org/10.7326/0003-4819-134-9_Part_1-200105010-00010

Zaghloul, A., El-Shattawy, H., Kassem, A., Ibrahim, E., Reddy, I., \& Khan, M. (2001). Honey, a prospective antibiotic: Extraction, formulation, and stability. Die Pharmazie, 56(8), 643-47.

Zargar, A. H., Bashir, M. I., Masoodi, S. R., Laway, B. A., Wani, A. I., Khan, A. R., \& Dar, F. A. (2002). Copper, zinc and magnesium levels in type-1 diabetes mellitus. Saudi Med J, 23(5), 539-42.

Zargar, A. H., Shah, N. A., Masoodi, S. R., Laway, B. A., Dar, F. A., Khan, A. R. ,Sofi, F. A., \& Wani, A. I. (1998). Copper, zinc, and magnesium levels in non-insulin dependent diabetes mellitus. Postgrad Med J, 74(877), 665-68. https://doi.org/10.1136/pgmj.74.877.665

\section{Copyrights}

Copyright for this article is retained by the author(s), with first publication rights granted to the journal.

This is an open-access article distributed under the terms and conditions of the Creative Commons Attribution license (http://creativecommons.org/licenses/by/4.0/). 